\title{
Recollection
}

\section{Zongluo Luo, a Chinese Haigui in 1930s}

\author{
Ming Li, Le Kang \\ Beijing Institutes of Life Science, Chinese Academy of Sciences, Beijing 100101, China
}

\begin{abstract}
"Haigui," which pronounces the same in Chinese as that of sea turtle, has become a trendy word in modern China. For those of you who are not familiar with the word yet, Haigui is a homonym for returnee from overseas. To overseas-educated Chinese scholars, the idea of returning home becomes more and more enticing because of China's rapid economic growth. Until 2010, nearly half a million of Chinese have returned from overseas. And the trend has no exception in the life science academia. Scientists are attracted back home for promising research environment and rising salaries. Many returnees say that the lab environment they have got here in China definitely trumps what they could expect in the United States or Europe. Why wouldn't they have returned? However, their earlier counterparts back in the old days were not as lucky as they are nowadays. In the 1920s and 1930s, scientists returned for completely different reasons.
\end{abstract}

Along with the transformation of the social framework and political structure, China's academic system was going through dramatic changes in the 1920s — from the traditional system where Confucius meant everything and natural sciences meant nothing, to the relatively modern educational system with colleges and universities being established everywhere. All the newly-established colleges and universities were in desperate need of faculty who were familiar with modern academic system and modern science; thus many foreign-trained Chinese scholars were recruited back home. They were never promised better academic opportunities or higher salaries, but they still returned in hopes of bringing modern knowledge to their home country and their people. Among these returnees there were the lucky ones, who managed to start teaching right away and/or set up their own labs in a short period of time, considering the poor economic environment and political instability at that time. Then there were the less fortunate ones, who struggled a long time before they could settle down and do what they had expected to be doing upon returning. Professor Zongluo Luo (Tsung-lo Lo), a main founder of modern plant physiology in China, would qualify for the latter group.

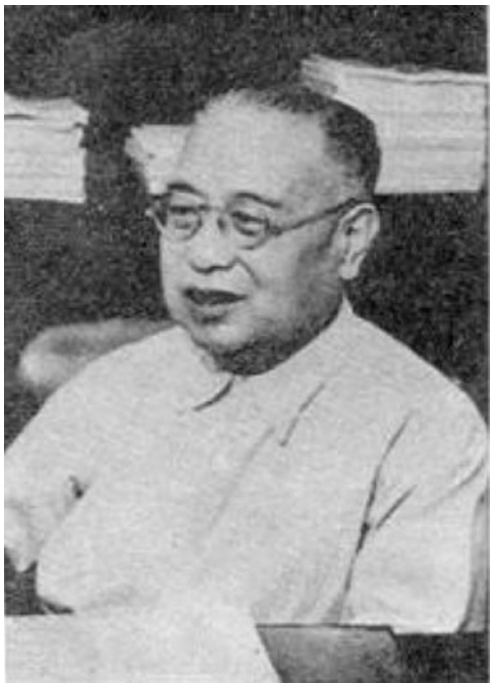

Zongluo Luo

Zongluo Luo was born in 1898 in a merchant's family in Zhejiang province. After receiving his early education at Hangzhou Anding Middle School and Shanghai Nanyang High School, he traveled to Japan to receive higher education. He spent eight years at Hokkaido University for the undergraduate and graduate programs, and obtained his Ph.D. degree from Hokkaido University in 1930, which made him the second Chinese who got a Ph.D. degree in Japan. After graduation, Zongluo Luo accepted an offer from the Sun Yat-Sen University, Guangzhou, and returned China in February 1930.

When he first came back to Department of Biology at the Sun Yat-Sen University, Zongluo Luo was surprised to find how empty the department was. For a biology department, it was short of every essential element-textbooks, lab space, equipments, animal or plant specimens, etc. Even with the extreme lack of resources and funding, Zongluo Luo managed to start teaching, with hand-written textbooks 
made by himself. He even started his own plant physiology laboratory, no matter how simple and shabby it was. But the university itself became more and more unstable, and it went through four different presidents in two years, each having their own policy towards Department of Biology. With instability like this, it was meaningless for Zongluo Luo to continue pursuing his dream as an educator and a plant physiologist at the Sun Yat-Sen University. Thus he submitted his resignation letter and left the university in 1932.

The second university Zongluo Luo worked at was Jinan University in Shanghai. The president of Jinan University offered him a professor position and promised to help him build his own laboratory. However, all the promises of funding for purchasing lab equipments and reagents and hiring assistants turned out to be empty ones after all. All he could do during his one year in Jinan University was to teach general biology. Feeling disappointed and hoping to put his talent and knowledge into better use, Zongluo Luo left Jinan University for the National Central University in 1933.

Compared to the other two universities he had stayed in, the National Central University was definitely more developed in many respects - more faculty, more students, and more budget. Zongluo Luo was assigned to teach three courses which kept him busy all year long. But he never thought of the heavy teaching task as a burden; he couldn't be happier that he could be so busy. He also managed to get relatively sufficient funding from the university, which was not easy as the competition among faculty was quite intense. With the money, he was able to set up his own plant physiology lab in 1934 and published his first article after his return in 1935. But the good time did not last long. The university moved to Chongqing, Sichuan province, in 1937 during the antiJapanese war and the infrastructure of the university became fragile and the infighting among faculty became even more intense. Since most faculty members received their training in western countries, Zongluo Luo, a returnee from Japan, was always a minority in the university. In 1940, he felt that the university was no longer suitable for him and moved on to Zhejing University.

Like other Chinese universities during war time, Zhejing University had moved to Guizhou province and the biology department was located in a small town, Meitan, a safe and beautiful town with nothing more to offer. While he was teaching two courses in Meitan, Zongluo Luo also managed to establish a make-shift plant physiology laboratory in a disused ancestral temple, continuing his research on trace elements in plants. His teaching and research went on in Meitan until 1944 when he was appointed the Director of the Botany Research Institute of Academia Sinica in Chongqing, where he could have a real laboratory and his career really took off.

Fourteen years and four universities, before Zongluo Luo finally found the right place to do what really interested him and began to fulfill his dream. Some people would give up and maybe go overseas again for better opportunities; others would face the reality and be happy with whatever they had got. But Zongluo Luo never stopped until he found what he was looking for. Meanwhile, no matter how difficult the journey was and how far the reality was from his dream, he never wasted any time. Instead, in all of the four universities he had stayed, he always devoted himself to his work and gathered all his energy to make a positive difference. People regard him as a main founder of Chinese plant physiology, not only based on the academic achievement he had made at the Botany Research Institute, but also because of the large number of young students he had trained in the universities, many of whom became the backbone of China plant physiology later. 